\title{
Numerical and Analytical Study of Two Dimensional Heat Transfer Thorough an Annular Fin of Variable Thickness \\ Ziad M. Al-Makhyoul \\ Lecturer
}

Department of Mechanical Engineering-University of Mosul-Iraq

\section{Abstract}

This paper included an analytical study of a two dimensional (radial and transverse) heat flow through annular fin variable thickness analytically depending on the group of resistances by derivating the major equations of conduction and convection. The total resistance equation of fin is derived to be general and simple model to calculate the heat flow and to study the effect of fin parameters on it.

A numerical solution is added to prove the validity of the analytical solution by using a grid generation transformation-algebraic method to regulating the irregular mesh on the fin surface.

Finally, the results show a good agreement between the two solutions using a wide range of fin parameters and this study is supposed to facilitate the designing of fin to the designer.

Key words: Annular fin , Total resistance, heat transfer coefficient

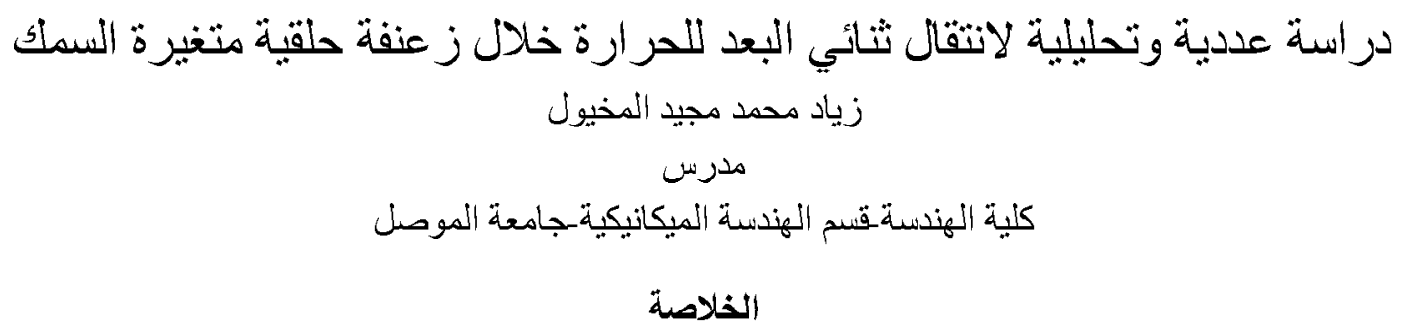




\section{Nomenclature}

A

h Heat transfer coefficient

K Thermal conductivity

M Number of grid in transverse direction

$\mathrm{N} \quad$ Number of grid in transverse direction

QFn Heat transfer from fin numerically

$\mathrm{QF}_{\text {th }} \quad$ Heat transfer from fin theoretically

ri Inner radius of fin

ro Outer radius of fin

$\mathrm{R}_{\mathrm{L}} \quad$ Longitudinal resistance

$\mathrm{R}_{\mathrm{m}} \quad$ Material resistance

$\mathrm{R}_{\mathrm{S}} \quad$ Surface resistance

$\mathrm{R}_{\mathrm{t}} \quad$ Transverse resistance

T Temperature

$\mathrm{T}_{\mathrm{b}}$

$\mathrm{T}_{\mathrm{f}}$

$\mathrm{TR}_{\text {th }}$

wi

wo

r

Z

$\xi$

$\eta$

$\theta$

Base temperature

horizontal direction in physical model

Vertical direction in physical model

Horizontal direction in calculated model

Vertical direction in calculated model

Inclination of fin thikness

$\mathrm{m}^{2}$

$\mathrm{W} / \mathrm{m}^{2} \cdot{ }^{\circ} \mathrm{K}$

$\mathrm{W} / \mathrm{m} .{ }^{\circ} \mathrm{K}$

W

W

$\mathrm{m}$

m

${ }^{\circ} \mathrm{C} / \mathrm{W}$

${ }^{\circ} \mathrm{C} / \mathrm{W}$

${ }^{\circ} \mathrm{C} / \mathrm{W}$

${ }^{\circ} \mathrm{C} / \mathrm{W}$

${ }^{\circ} \mathrm{C}$

${ }^{\circ} \mathrm{C}$

${ }^{\circ} \mathrm{C}$

${ }^{\circ} \mathrm{C} / \mathrm{W}$

m

m 
$\begin{array}{llll}\text { Al-Rafidain Engineering } & \text { Vol.19 } & \text { No.1 } & \text { February } 2011\end{array}$

\section{Introduction:}

Annular fins find numerous applications in compact heat exchangers: in specialized installations of single and double-pipe heat exchangers, in electrical apparatus in which generated heat must be efficiently dissipated, on cylinders of air cooled internal-combustion engines. Many researchers work in this field for a long time ago until now.

Higges [1] studied the heat transfer from annular fins of triangular profile with variable heat transfer coefficient from the base to the tip. He found that the increase in the heat transfer coefficient will cause the decrease in the efficiency of the fin.

Kundu \& Das [2] studied the analysis and optimization of annular fins with variable heat transfer coefficient along the fin surface. They determined analytically the temperature profiles fin by using the Frobenius expanding series. Simplifying assumptions like arc idealization and the insulated fin tip condition have been relaxed and a linear variation of the convective heat transfer coefficient along the fin surface has been taken into account.

Kahwaji [3] conducted a numerical and electrical analogue study of the thermal performance of annular fins of constant thickness under one and two dimensional heat flow assumption. He suggested a new simple method for correlating the fin rate of heat transfer which depends on the grouping of the different thermal resistances of the fin in a (driving force / resistance) form model. Where $\mathrm{TR}_{\mathrm{th}}$ is the total resistance of the fin and the term under the square root is the two - dimensional material resistance, while the other term is the surface resistance. The above form of correlation was found to give an accurate representation of the heat transfer from the fin.

Al-Makhyoul [4] conducted detailed experiments to validate the resistance model in [1] experimentally. The experiments covered both the natural and forced convection heat transfer modes using fins of different materials and dimensions. The results indicated a good agreement between the suggested model and the experimental findings, where the calculated and measured heat fluxs were found to be within less than $(8.33 \%)$ in the natural convection tests and (11\%) in the forced convection tests.

Kahwaji and Al-Makhyoul [5] derived analytically the total resistance model by using the variable heat transfer coefficient in two dimensional heat flow for annular fin constant thickness by using a finite difference method using SOR technique. The study covered a wide range of fin parameters and heat transfer coefficient models. The results were in agreement and proved the validity of the suggested equation model and this model can be used in the constant or variable heat transfer coefficient in the heat transfer calculation for annular fins.

Al-Niamey [6] investigated the outlines experimentally of the total resistance model for the heat dissipation when they are applied to longitudinal fin at a constant heat transfer 
coefficient was constant. The study covered the natural and forced convection heat transfer in order to cover the wide range of heat transfer coefficient, lengths, thicknesses and heat flux. A finite difference technique was used to prove the validity of the experimental results. Finally, the results proved the validity of the suggested model where the maximum difference between the experimental and the numerical solutions was $8.6 \%$ and $14 \%$ in the natural and forced convection experiments respectively.

The above literature indicated that [1 and 2] were concerned with the heat flow through extended surface by using either charts or a computer program, while the researchers [3 to 6] were concerned with the studying of the heat transfer calculations depending on total resistance model for annular and longitudinal fins with constant thickness and their results were good. This model is distinguished as the simplest one to be used compared with those which are used either in charts or a computer used in the heat rate estimation. In this paper, the total resistance model will be derived analytically for the annular fin by using variable thickness (trapezoidal cross section area) and studied the effect of fin parameter of all resistances that to be affected on the heat flow through fin and its validity will be numerically investigated to high range of parameters. This model makes it easy to the designer to choose the parameter of fin through the design.

\section{The Analytical Solution:}

The analysis for the heat transfer through the annular fin with trapezoidal cross section by using the resistances model can be divided into three terms, longitudinal, transverse and surface resistances as shown in figure (1) .

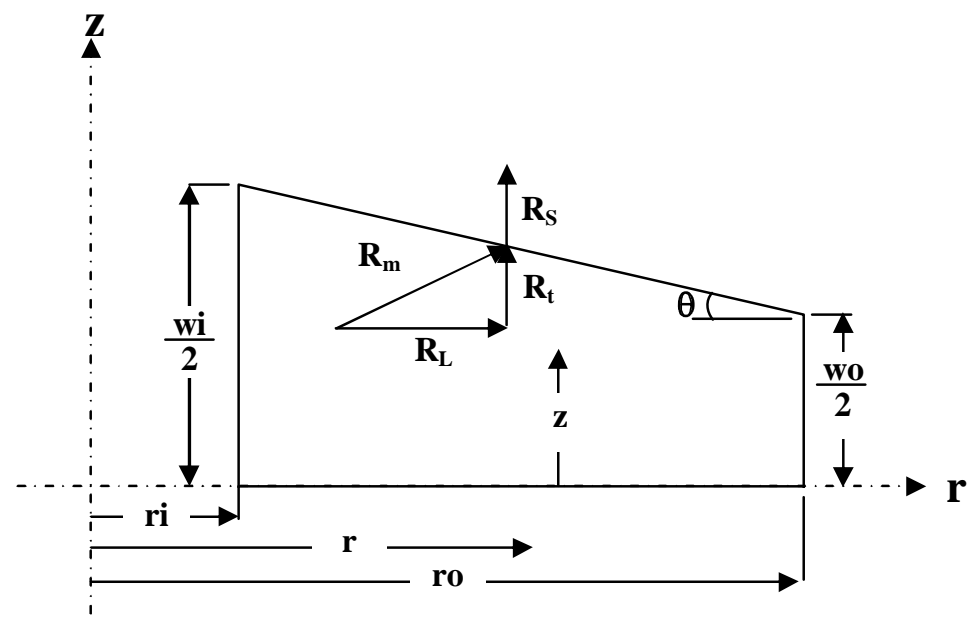

Figure (1) schematic diagram for the semi- fin

Where $\mathrm{TR}=\sqrt{\mathrm{R}_{\mathrm{L}}{ }^{2}+\mathrm{R}_{\mathrm{t}}{ }^{2}}+\mathrm{R}_{\mathrm{s}}$ 
For the longitudinal resistance, the heat transfer equation according Forrier theorem can be written as follows:

$\mathrm{q}=-\mathrm{k} \int(\mathrm{dA}) \frac{\mathrm{dT}}{\mathrm{dr}}$

The longitudinal resistance will be as:

$$
\begin{aligned}
& \mathrm{R}_{\mathrm{L}}=-\mathrm{k} \int \frac{\mathrm{dr}}{2 \pi \mathrm{rz}}, \text { where } \mathrm{z}=\frac{1}{2}\left[\frac{(\mathrm{wi}-\mathrm{wo})(\mathrm{ro}-\mathrm{r})}{(\mathrm{ro}-\mathrm{ri})}+\text { wo }\right] \\
& \mathrm{R}_{\mathrm{L}}=\frac{\mathrm{ro}-\mathrm{ri}}{4 \pi \mathrm{k}} \int_{\mathrm{ri}}^{\mathrm{ro}} \frac{\mathrm{dr}}{\left(\mathrm{wi}^{*} \text { ro }-\mathrm{wo}^{*} \mathrm{ri}\right) \mathrm{r}+(\mathrm{wo}-\mathrm{wi}) \mathrm{r}^{2}}
\end{aligned}
$$

After simplifying the equation above and carrying out the integration for equation (3), the longitudinal resistance can be written as follows:

$$
\mathrm{R}_{\mathrm{L}}=\frac{(\text { ro }-\mathrm{ri}) \ln \frac{\lambda(\gamma-\zeta \mathrm{ri})}{\gamma-\zeta \mathrm{ro}}}{4 \pi \mathrm{k} \gamma}
$$

where: $\lambda=($ ro $/$ ri $), \zeta=($ wi - wo $), \gamma=($ wi $*$ ro - wo $*$ ri $)$

The transverse resistance could be obtained by using a Forrier heat equation carried out the integration, the transverse resistance yields:

$$
\mathrm{q}=-\mathrm{k} j(\mathrm{dA}) \frac{\mathrm{dT}}{\mathrm{dz}}
$$

after integration the transverse resistance is given as:

$$
\mathrm{R}_{\mathrm{t}}=\frac{(\mathrm{wi}-\mathrm{wo}) \cos \theta+\mathrm{wo}}{4 \pi \mathrm{k}\left(\mathrm{ro}^{2}-\mathrm{ri}^{2}\right)} \text { where } \theta=\tan ^{-1} \frac{w i-w o}{r o-r i}
$$

The surface resistance analysis includes both sides of fin and the equation of surface resistance is given as:

$$
\begin{aligned}
& q=h\lceil(d A) \Delta T \\
& \mathrm{R}_{\mathrm{s}}=\frac{\cos \theta}{2 \pi \mathrm{h}\left(\mathrm{ro}^{2}-\mathrm{ri}^{2}\right)}
\end{aligned}
$$

The total resistance for the annular fin trapezoidal section is:

$\mathrm{TR}=\sqrt{\mathrm{R}_{\mathrm{L}}{ }^{2}+\mathrm{R}_{\mathrm{t}}{ }^{2}}+\mathrm{R}_{\mathrm{s}}$ Then:

$$
\mathrm{TR}_{\mathrm{th}}=\sqrt{\left(\frac{(\mathrm{ro}-\mathrm{ri}) \ln \frac{\lambda(\gamma-\zeta \mathrm{ri})}{\gamma-\zeta \mathrm{ro}}}{4 \pi \mathrm{k} \gamma}\right)^{2}+\left(\frac{(\mathrm{wi}-\mathrm{wo}) \cos \theta+\mathrm{wo}}{4 \pi \mathrm{k}\left(\mathrm{ro}^{2}-\mathrm{ri}^{2}\right)}\right)^{2}+\frac{\cos \theta}{2 \pi \mathrm{h}\left(\mathrm{ro}^{2}-\mathrm{ri}^{2}\right)}}
$$




$$
\mathrm{QF}_{\mathrm{th}}=\frac{\left(\mathrm{T}_{\mathrm{b}}-\mathrm{T}_{\mathrm{f}}\right)}{\mathrm{TR}_{\mathrm{th}}}
$$

\section{The Numerical Solution:}

Many equations could be applied for any type of fin. All of these equations were derived from the general heat conduction equation under different simplifying assumptions and boundary conditions:

1-The heat flow and temperature distributions throughout the fin are independent of time.

2-The fin material is homogenous.

3-There is no heat source inside the fin.

4-The heat flow from the fin surface at any point is directly proportional to the temperature difference between the surface and surrounding fluid at that point.

5-The thermal conductivity of the fin material is constant.

6-The heat transfer coefficient is constant or variable along the fin surface.

7-The temperature of the surrounding fluid is constant and the base of the fin is isothermal.

The assumptions above are inherent with the two-dimensional conduction equation in polar coordinates that should be solved numerically in order to investigate the validity of the total resistance model. The fin was divided in to the radial and transverse directions to ( $\mathrm{N}$ and $\mathrm{M}$ ) from divisions. The thickness of each one was $(\Delta \mathrm{r}$ and $\Delta \mathrm{z})$ in the radial and transverse directions.

The general equation for the temperature distribution in the two dimensional heat flow case can be shown as:

$$
\frac{\partial^{2} \mathrm{~T}}{\partial \mathrm{r}^{2}}+\frac{1}{\mathrm{r}} \frac{\partial \mathrm{T}}{\partial \mathrm{r}}+\frac{\partial^{2} \mathrm{~T}}{\partial \mathrm{z}^{2}}=0.0
$$

In this paper the grid generation algebraic method is used to convert the irregular mish on the fin surface to the regular mish by transforming the physical coordinate ( $\mathrm{r}$ and $\mathrm{z}$ ) to calculated coordinate ( $\xi$ and $\eta$ ) as shown in figure (2) with equal interval between the nodes $(\Delta \xi$ and $\Delta \eta$ equal 1.0$)$.
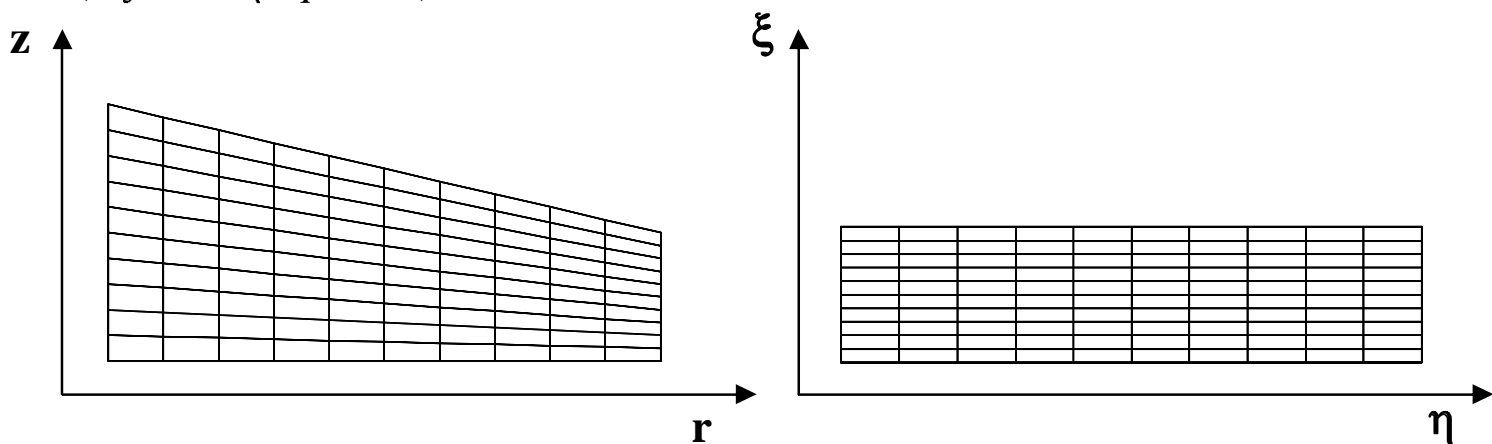

Figure (2) the transformation method to regular grid 
Every term of the general equation is converted to calculate the coordinate $(\xi, \eta)$ and the equations can be written as:

$$
\begin{aligned}
& \frac{\partial \mathrm{T}}{\partial \mathrm{r}}=\frac{\partial \mathrm{T}}{\partial \xi} * \frac{\partial \xi}{\partial \mathrm{r}}+\frac{\partial \mathrm{T}}{\partial \eta} * \frac{\partial \eta}{\partial \mathrm{r}}[7] \\
& \frac{\partial \mathrm{T}}{\partial \mathrm{z}}=\frac{\partial \mathrm{T}}{\partial \xi} * \frac{\partial \xi}{\partial \mathrm{z}}+\frac{\partial \mathrm{T}}{\partial \eta} * \frac{\partial \eta}{\partial \mathrm{z}}[7] \\
& \frac{\partial^{2} \mathrm{~T}}{\partial \mathrm{r}^{2}}=\left(\frac{\partial \mathrm{T}}{\partial \xi} * \frac{\partial^{2} \xi}{\partial \mathrm{r}^{2}}\right)+\left(\frac{\partial \mathrm{T}}{\partial \eta} * \frac{\partial^{2} \eta}{\partial \mathrm{r}^{2}}\right)+\left(\frac{\partial^{2} \mathrm{~T}}{\partial \xi^{2}}\right)\left(\frac{\partial \xi}{\partial \mathrm{r}}\right)^{2}+\left(\frac{\partial^{2} \mathrm{~T}}{\partial \eta^{2}}\right)\left(\frac{\partial \eta}{\partial \mathrm{r}}\right)^{2}+2\left(\frac{\partial^{2} \mathrm{~T}}{\partial \eta \partial \xi}\right)\left(\frac{\partial \eta}{\partial \mathrm{r}}\right)\left(\frac{\partial \xi}{\partial \mathrm{r}}\right)[7]
\end{aligned}
$$

The derivatives $\frac{\partial \mathrm{T}}{\partial \xi}, \frac{\partial \mathrm{T}}{\partial \eta}, \frac{\partial^{2} \mathrm{~T}}{\partial \eta^{2}}, \frac{\partial^{2} \mathrm{~T}}{\partial \xi^{2}}$ and $\frac{\partial^{2} \mathrm{~T}}{\partial \xi \partial \eta}$ undergo to central finite difference Tyler series for temperature with respect to $\eta, \xi$ as:

$$
\begin{aligned}
& \left(\frac{\partial f}{\partial x}\right)=\frac{f(i+1, j)-f(i-1, j)}{2 \Delta x} \text { and }\left(\frac{\partial f}{\partial y}\right)=\frac{f(i, j+1)-f(i, j+1)}{2 \Delta y} \\
& \left(\frac{\partial^{2} \mathrm{~T}}{\partial \mathrm{r}^{2}}\right)=\frac{f(i+1, j)-2 f(i, j)+f(i-1, j)}{(\Delta r)^{2}} \text { and }\left(\frac{\partial^{2} \mathrm{~T}}{\partial \mathrm{z}^{2}}\right)=\frac{f(i, j+1)-2 f(i, j)+f(i, j-1)}{(\Delta \mathrm{z})^{2}} \\
& \left(\frac{\partial^{2} \mathrm{~T}}{\partial \mathrm{r} \partial \mathrm{z}}\right)=\frac{\mathrm{f}(\mathrm{i}+1, \mathrm{j}+1)-\mathrm{f}(\mathrm{i}-1, \mathrm{j}+1)-\mathrm{f}(\mathrm{i}+1, \mathrm{j}-1)+\mathrm{f}(\mathrm{i}-1, \mathrm{j}-1)}{4 \Delta \mathrm{r} \Delta \mathrm{z}} \\
& \left(\frac{\partial \xi}{\partial \mathrm{r}}\right)=\left(\frac{\partial \mathrm{z}}{\partial \eta}\right) \frac{1}{\mathrm{Jac}}[7] \\
& \left(\frac{\partial \eta}{\partial \mathrm{r}}\right)=-\left(\frac{\partial \mathrm{z}}{\partial \xi}\right) \frac{1}{\mathrm{Jac}}[7] \\
& \left(\frac{\partial \xi}{\partial \mathrm{z}}\right)=-\left(\frac{\partial \mathrm{r}}{\partial \eta}\right) \frac{1}{\mathrm{Jac}}[7] \\
& \left(\frac{\partial \eta}{\partial \mathrm{z}}\right)=\left(\frac{\partial \mathrm{r}}{\partial \xi}\right) \frac{1}{\mathrm{Jac}}[7]
\end{aligned}
$$

Where Jac is Jacobian matrix and the derivatives $\frac{\partial \mathrm{z}}{\partial \xi}, \frac{\partial \mathrm{z}}{\partial \eta}, \frac{\partial \mathrm{r}}{\partial \xi}$ and $\frac{\partial \mathrm{r}}{\partial \eta}$ undergo to central finite difference Tyler series for temperature with respect to $\eta, \xi$ as equations (15) $\mathrm{Jac}=\left[\left(\frac{\partial \mathrm{r}}{\partial \mathrm{z}}\right)\left(\frac{\partial \mathrm{z}}{\partial \eta}\right)\right]-\left[\left(\frac{\partial \mathrm{r}}{\partial \eta}\right)\left(\frac{\partial \mathrm{z}}{\partial \xi}\right)\right][7]$ 
By making a derivative to the equations (18 and 19) with respect to (r) and equations (20 and 21) with respect to (z) the result will be as:

$$
\begin{aligned}
& \frac{\partial^{2} \xi}{\partial \mathrm{r}^{2}}=\frac{-1}{\mathrm{Jac}^{2}}\left[\left(\frac{\partial \mathrm{z}}{\partial \eta}\right) \mathrm{Jac}_{\mathrm{r}}-\left[\left(\frac{\partial^{2} \mathrm{z}}{\partial \eta \partial \xi}\right)\left(\frac{\partial \mathrm{z}}{\partial \eta}\right)-\left(\frac{\partial^{2} \mathrm{z}}{\partial \eta^{2}}\right)\left(\frac{\partial \mathrm{z}}{\partial \xi}\right)\right]\right] \\
& \frac{\partial^{2} \xi}{\partial \mathrm{z}^{2}}=\frac{1}{\mathrm{Jac}^{2}}\left[\left(\frac{\partial \mathrm{r}}{\partial \eta}\right) \mathrm{Jac}_{\mathrm{z}}-\left[\left(\frac{\partial^{2} \mathrm{r}}{\partial \eta^{2}}\right)\left(\frac{\partial \mathrm{r}}{\partial \xi}\right)-\left(\frac{\partial^{2} \mathrm{r}}{\partial \eta \partial \xi}\right)\left(\frac{\partial \mathrm{r}}{\partial \eta}\right)\right]\right] \\
& \frac{\partial^{2} \eta}{\partial \mathrm{r}^{2}}=\frac{1}{\mathrm{Jac}^{2}}\left[\left(\frac{\partial \mathrm{z}}{\partial \xi}\right) \mathrm{Jac}_{\mathrm{r}}-\left[\left(\frac{\partial^{2} \mathrm{z}}{\partial \xi^{2}}\right)\left(\frac{\partial \mathrm{z}}{\partial \eta}\right)-\left(\frac{\partial^{2} \mathrm{z}}{\partial \eta \partial \xi}\right)\left(\frac{\partial \mathrm{z}}{\partial \xi}\right)\right]\right] \\
& \frac{\partial^{2} \eta}{\partial \mathbf{z}^{2}}=\frac{-1}{\mathrm{Jac}^{2}}\left[\left(\frac{\partial \mathrm{r}}{\partial \xi}\right)_{\mathrm{i}, \mathrm{j}} \mathrm{Jac}_{\mathrm{z}}-\left[\left(\frac{\partial^{2} \mathrm{r}}{\partial \eta \partial \xi}\right)\left(\frac{\partial \mathrm{r}}{\partial \xi}\right)-\left(\frac{\partial^{2} \mathrm{r}}{\partial \xi^{2}}\right)\left(\frac{\partial \mathrm{r}}{\partial \eta}\right)\right]\right]
\end{aligned}
$$

Where, ( $\mathrm{Jac}_{\mathrm{r}}$ and $\mathrm{Jac}_{\mathrm{z}}$ ) represented the derivative of (22) with respect to $\mathrm{r}$ and $\mathrm{z}$ and, where $\left(\mathrm{Jac}_{\eta}\right.$, and $\left.\mathrm{Jac}_{\xi}\right)$ represented the derivative of (22) with respect to $\eta$ and $\xi$.

The derivatives $\frac{\partial^{2} \mathrm{r}}{\partial \xi^{2}}, \frac{\partial^{2} \mathrm{r}}{\partial \eta^{2}}, \frac{\partial^{2} \mathrm{z}}{\partial \xi^{2}}, \frac{\partial^{2} \mathrm{z}}{\partial \eta^{2}}, \frac{\partial^{2} \mathrm{r}}{\partial \xi \partial \eta}$ and $\frac{\partial^{2} \mathrm{z}}{\partial \xi \partial \eta}$ undergo to central finite difference Tyler series for temperature in equations (16 and 17) with respect to $\eta, \xi$.

After simplifying and substituting the equations above, the equation of temperature distribution in the interior node is yield as:

$$
T(i, j)=\frac{A T(i-1, j)+B T(i+1, j)+C T(i, j-1)+D T(i, j+1)+E}{A+B+C+D}
$$

when:

$$
\begin{aligned}
& \mathrm{A}=\left(\frac{\partial \xi}{\partial \mathrm{r}}\right)^{2}+\left(\frac{\partial \xi}{\partial \mathrm{z}}\right)-0.5 *\left(\left(\frac{\partial^{2} \xi}{\partial \mathrm{r}^{2}}\right)+\left(\frac{\partial^{2} \xi}{\partial \mathrm{z}^{2}}\right)\right)-\frac{0.5}{\mathrm{r}} *\left(\frac{\partial \xi}{\partial \mathrm{r}}\right) \\
& \mathrm{Jac}_{\varsigma}=\left(\frac{\partial^{2} \mathrm{r}}{\partial \xi^{2}}\right)\left(\frac{\partial \mathrm{z}}{\partial \eta}\right)+\left(\frac{\partial^{2} \mathrm{z}}{\partial \xi \partial \eta}\right)\left(\frac{\partial \mathrm{r}}{\partial \xi}\right)-\left(\frac{\partial^{2} \mathrm{r}}{\partial \xi \partial \eta}\right)\left(\frac{\partial \mathrm{z}}{\partial \xi}\right)-\left(\frac{\partial^{2} \mathrm{z}}{\partial \xi^{2}}\right)\left(\frac{\partial \mathrm{r}}{\partial \eta}\right) \\
& \mathrm{C}=\left(\frac{\partial \eta}{\partial \mathrm{r}}\right)^{2}+\left(\frac{\partial \eta}{\partial \mathrm{z}}\right)-0.5 *\left(\left(\frac{\partial^{2} \eta}{\partial \mathrm{r}^{2}}\right)+\left(\frac{\partial^{2} \eta}{\partial \mathrm{z}^{2}}\right)\right)-\frac{0.5}{\mathrm{r}} *\left(\frac{\partial \eta}{\partial \mathrm{r}}\right) \\
& \mathrm{D}=\left(\frac{\partial \eta}{\partial \mathrm{r}}\right)^{2}+\left(\frac{\partial \eta}{\partial \mathrm{z}}\right)+0.5\left(\left(\frac{\partial^{2} \eta}{\partial \mathrm{r}^{2}}\right)+\left(\frac{\partial^{2} \eta}{\partial \mathrm{z}^{2}}\right)\right)+\frac{0.5}{\mathrm{r}} *\left(\frac{\partial \eta}{\partial \mathrm{r}}\right) \\
& \mathrm{E}=2\left(\frac{\partial \xi}{\partial \mathrm{r}} \cdot \frac{\partial \eta}{\partial \mathrm{r}}+\frac{\partial \xi}{\partial \mathrm{z}} \cdot \frac{\partial \eta}{\partial \mathrm{z}}\right)\left(\frac{\partial^{2} \mathrm{~T}}{\partial \mathrm{r} \partial \mathrm{z}}\right)
\end{aligned}
$$

when $1<\mathrm{i}<\mathrm{N}$ and $1<\mathrm{j}<\mathrm{M}$ 
The temperature distribution in the axis which divided the fin to two similar parts can be investigated as follows:

$$
\begin{gathered}
\frac{\partial \mathrm{T}}{\partial \mathrm{z}}=0 \\
\frac{\partial \mathrm{T}}{\partial \mathrm{z}}=\frac{\partial \mathrm{T}}{\partial \xi} \cdot \frac{\partial \xi}{\partial \mathrm{z}}+\frac{\partial \mathrm{T}}{\partial \eta} \cdot \frac{\partial \eta}{\partial \mathrm{z}}=0 \\
\mathrm{~T}(\mathrm{i}, \mathrm{j})=\frac{1}{3}\left[\left(\mathrm{~T}(\mathrm{i}+1, \mathrm{j})-\mathrm{T}(\mathrm{i}-1, \mathrm{j}) * \frac{\partial \xi}{\partial \mathrm{z}}+4 \mathrm{~T}(\mathrm{i}, \mathrm{j}+1)-\mathrm{T}(\mathrm{i}, \mathrm{j}+2) * \frac{\partial \eta}{\partial \mathrm{z}}\right)\right] \frac{1}{\frac{\partial \eta}{\partial \mathrm{z}}}
\end{gathered}
$$

when $1<\mathrm{i}<\mathrm{N}, \mathrm{j}=1$

$T_{\eta}$ and $r_{\eta}$ are calculated for $T, r$ with respect to $\eta$ as:

$$
\frac{\partial T}{\partial x}=\frac{4 f(i, j+1)-3 f(i, j)-f(i, j+2)}{2 \Delta x}
$$

To calculate the nodes for the temperature distribution in the tip of fin, we must use the backward difference for Tyler series as:

$$
\begin{aligned}
& \frac{\partial \mathrm{T}}{\partial \mathrm{r}}=0 \\
& \frac{\partial \mathrm{T}}{\partial \mathrm{r}}=\frac{\partial \mathrm{T}}{\partial \xi} \cdot \frac{\partial \xi}{\partial \mathrm{r}}+\frac{\partial \mathrm{T}}{\partial \eta} \cdot \frac{\partial \eta}{\partial \mathrm{r}}=0 \\
& \mathrm{~T}(\mathrm{i}, \mathrm{j})=\frac{1}{3}\left[\left(4 \mathrm{~T}(\mathrm{i}-1, \mathrm{j})-\mathrm{T}(\mathrm{i}-2, \mathrm{j})+\mathrm{T}(\mathrm{i}, \mathrm{j}-1)-\mathrm{T}(\mathrm{i}, \mathrm{j}+1) * \frac{\partial \eta}{\partial \mathrm{r}}\right)\right] \frac{1}{\frac{\partial \xi}{\partial \mathrm{r}}}
\end{aligned}
$$

when $\mathrm{i}=\mathrm{N}, 1<\mathrm{j}<\mathrm{M}$

$\mathrm{T}_{\xi}$ and $\mathrm{z}_{\xi}$ are calculated for $\mathrm{T}, \mathrm{z}$ with respect to $\xi$ as:

$$
\frac{\partial T}{\partial x}=\frac{f(i-2, j)+3 f(i, j)-4 f(i-1, j)}{2 \Delta x}
$$

To calculate the nodes for the temperature distribution in the surface of fin, we can use the heat balance method depending on the backward difference for Tyler series and the points around the point $T(i, j)$ as:

$$
T(i, j)=\frac{A 1 * T(i-1, j)+B 1 * T(i+1, j)+C 1 * T(i, j-1)+D 1 T_{f}}{E 1}
$$

where:

$\mathrm{A} 1, \mathrm{~B} 1$ and $\mathrm{C} 1$ represent the $(\mathrm{kA} / \mathrm{dx})$ on the surface in each point around $\mathrm{T}(\mathrm{i}, \mathrm{j})$.

D1 represents the heat conductance (hA) between the surface of fin and ambient. $\mathrm{E} 1=\mathrm{A} 1+\mathrm{B} 1+\mathrm{C} 1+\mathrm{D} 1$ 
The temperature for the corner points can be calculated as:

$$
\begin{aligned}
& \mathrm{T}(\mathrm{N}, 1)=(\mathrm{T}(\mathrm{N}-1,1)+\mathrm{T}(\mathrm{N}, 2)) / 2 \text { and } \mathrm{T}(\mathrm{N}, \mathrm{M})=(\mathrm{T}(\mathrm{N}-1, \mathrm{M})+\mathrm{T}(\mathrm{N}, \mathrm{M}-1)) / 2 \\
& \mathrm{QFn}=\sum_{\mathrm{i}=1}^{\mathrm{n}} \mathrm{h} * 2 \pi \mathrm{rS}(\mathrm{T}(\mathrm{i}, \mathrm{j})-\mathrm{Tf})
\end{aligned}
$$

Where, $\mathrm{S}$ is the distance of interval on the fin surface.

\section{Results and Discussions:}

Figure (3) shows the effect of fin length on the longitudinal, transverse and material resistances. Fin length is increase by the increasing of the outer radius of fin when the inner radius is constant. It is clear that the increase in fin length leads to the decrease in the transverse resistance which makes its effect very small. On the other hand, it is noted an increases in the longitudinal resistance and generally the material resistance. When the fin is long, the effect of resistances is neglected which makes this length not economic.

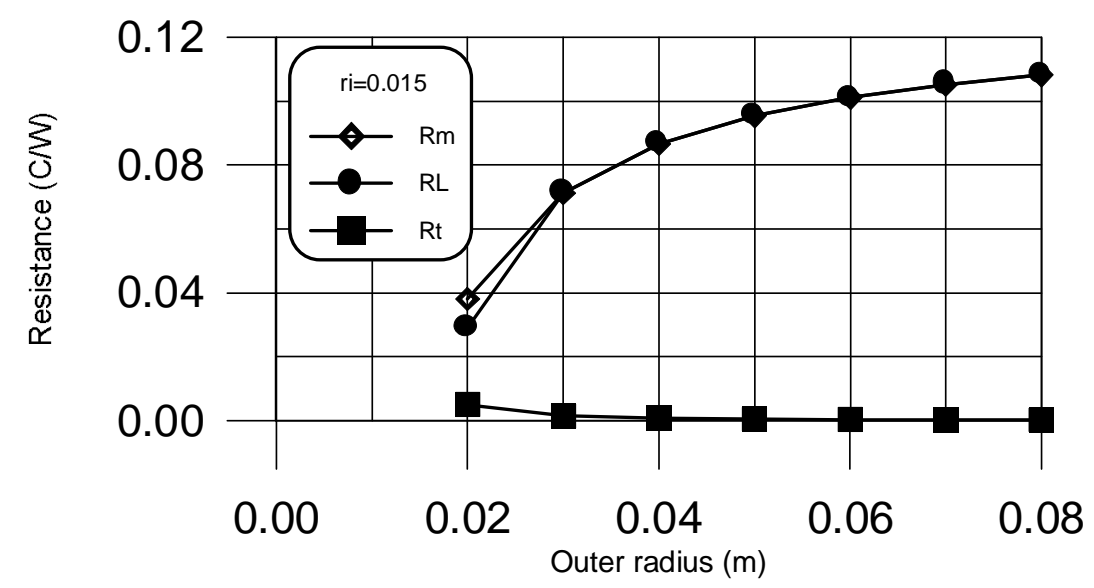

Figure (3) the relation between longitudinal resistance and fin length

Figure (4) represents the effect of length of fin on the longitudinal resistance by using many values of thermal conductivity. Generally, the increase in fin length causes an increase in the longitudinal resistance because the increase in the surface area, and this increase is clear at low value of thermal conductivity. When $(\mathrm{k})$ value starts to increase, the increase in the resistance becomes small, and $(\mathrm{k})$ value is being more effective from the surface area on the longitudinal resistance. 


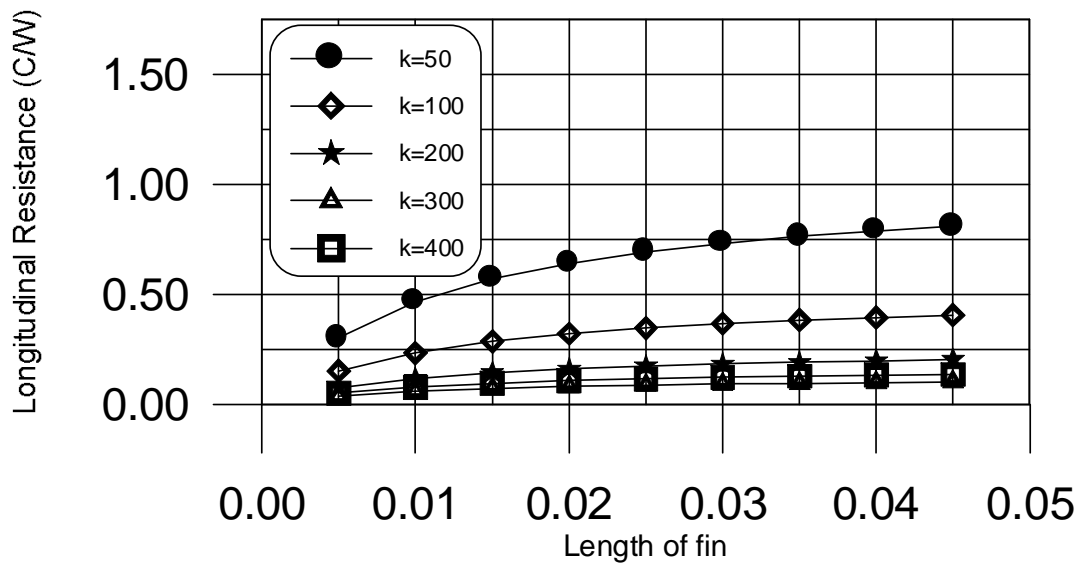

Figure (4) the relation between longitudinal resistance and fin length

The effect of fin length on the transverse resistance is clear in the figure (5). The increase in the fin length leads to an increase in the surface area and, then a decrease in the transverse resistance. At the small fin length, the increase in the $(\mathrm{k})$ value leads to a decrease in the resistance, while when the value of $(\mathrm{k})$ becomes high, the effect of $(\mathrm{k})$ will be slight. Generally, the transverse resistance curve decreases sharply when $(\mathrm{k})$ is small while the inclination of curve decreases when (k) is at a high value.

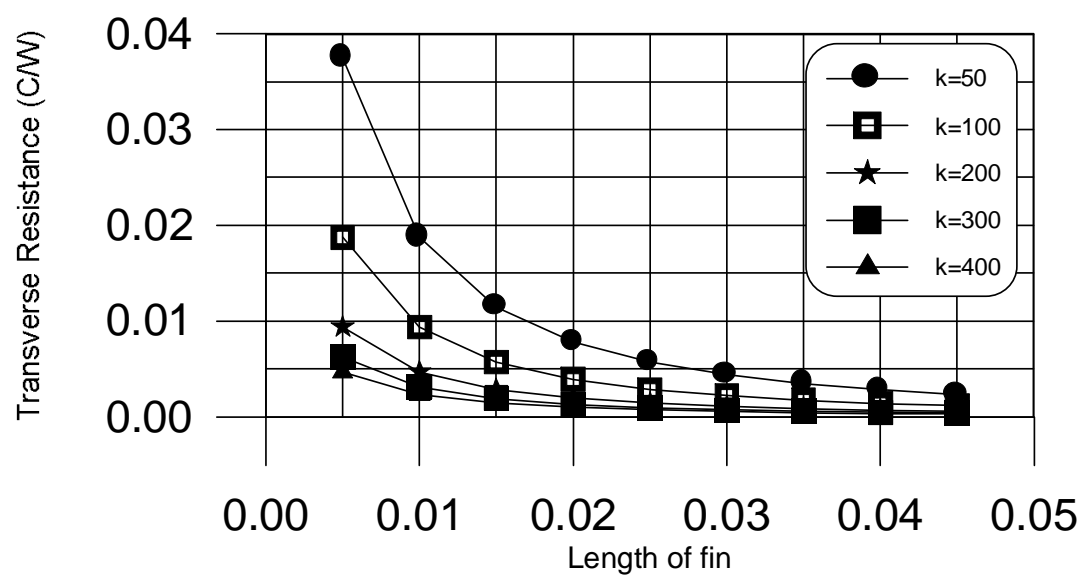

Figure (5) the relation between transverse resistance and fin length 
Figure (6) shows the relation between the surface resistance with length of fin. Generally, at the same length, the increase in the heat transfer coefficient leads to a decrease in the distribution value for heat transfer coefficient and, then a decrease in the convective resistance and finally the surface resistance. At the same heat transfer coefficient, the convective resistance decreases with the fin length because of the increase in the fin area and, then the decrease in the surface resistance.

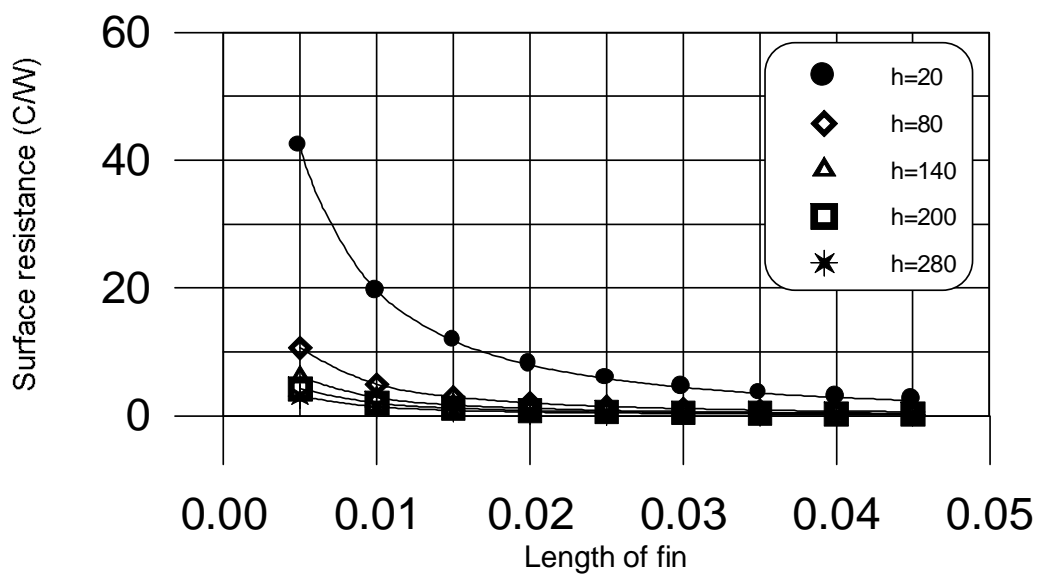

Figure (6) the relation between surface resistance and fin length

The total resistance is to be formed from the longitudinal, transverse and surface resistances, by the above analysis for each term. Generally, the increase in fin length leads to a decrease in the total resistance because when fin length increases the surface area is increased and makes a decrease in the surface resistance more than an increase in the longitudinal resistance as shown in figure (7). The curve starts to fall sharply from the infinite value, when the length of fin is very small and, then becomes approximately constant with the increase in length.

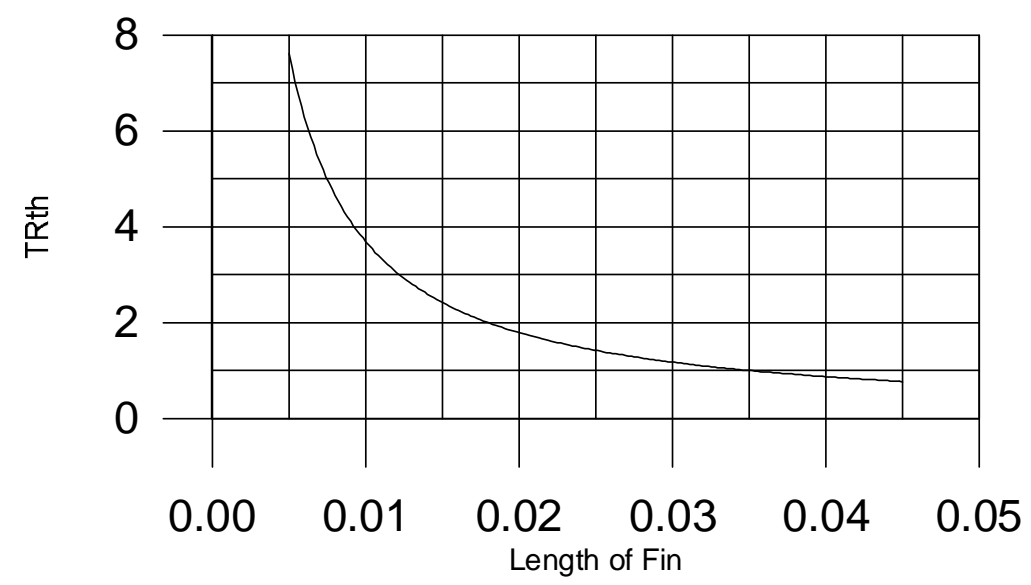

Figure (7) the relation between total resistance and fin length 


\section{$\begin{array}{llll}\text { Al-Rafidain Engineering } & \text { Vol.19 } & \text { No.1 } & \text { February } \\ 2011\end{array}$}

Figure (8) represents the change in the heat flux with the length of fin. The heat transfer will increase gradually along the fin .The material resistance increases and the surface resistance decreases with the length that will cause an increase in the temperature gradient and then an increase in the heat transfer from the fin. When the length is small, the rate of heat transfer is to be low and increases gradually with the length of fin until being constant and makes the increase in fin length not economic. The numerical results show a good agreement and confirm the validity of the total resistance model.

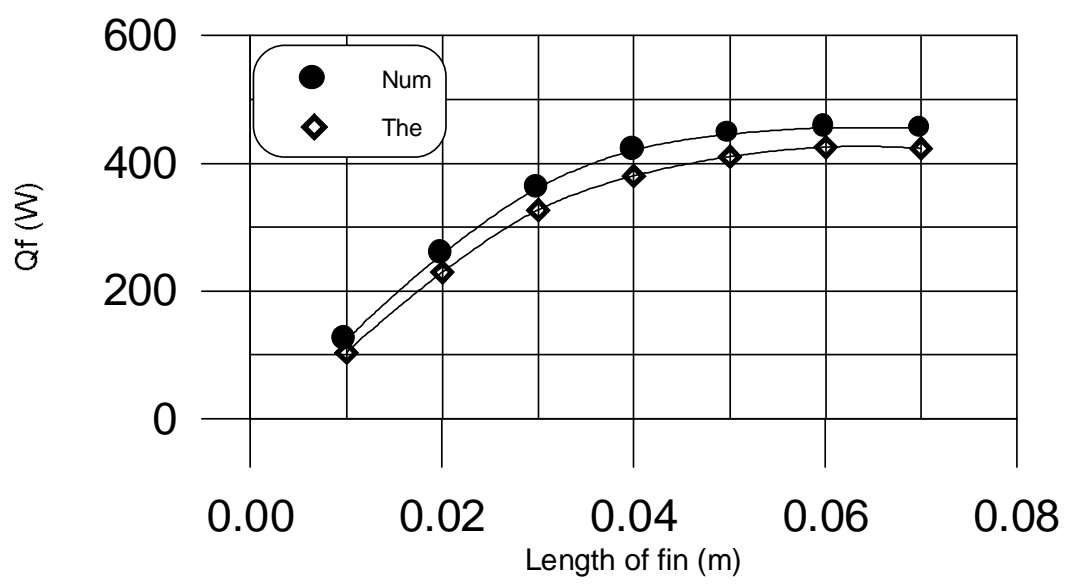

Figure (8) the relation between the heat transfer resistance and fin length

Figure (9) shows the effect of thermal conductivity on the resistance. The increase in the thermal conductivity causes the longitudinal resistance to be decreased hyperbolically, accordingly the total resistance is also decreased in the same pattern. It is clear that at the high value of thermal conductivity the surface resistance becomes the determining factor and the total resistance remains almost constant. Generally, the high and low values of thermal conductivity make the effect of the transverse resistance very small.

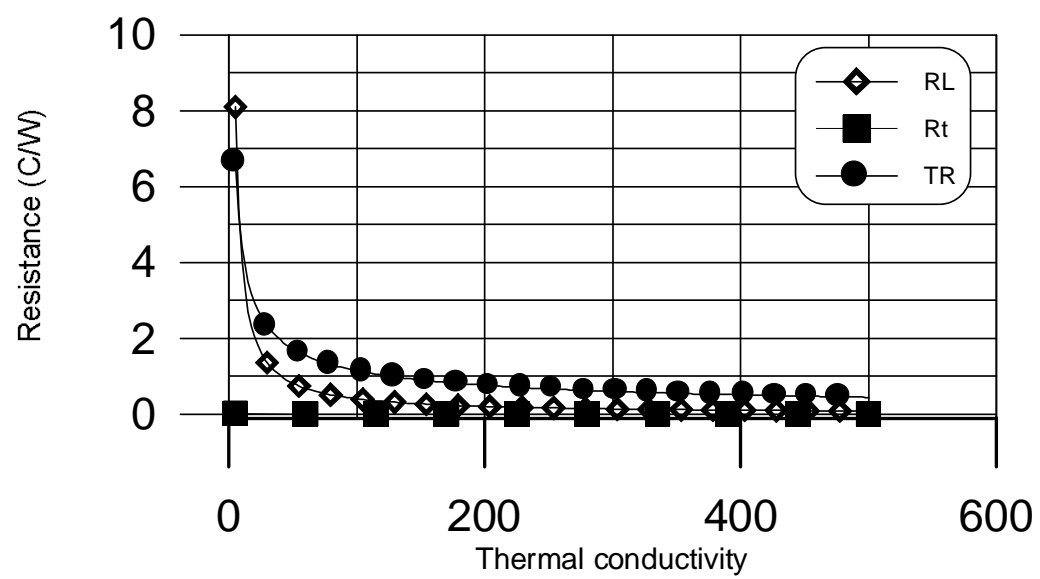

Figure (9) the relation between group of material resistance and thermal conductivity 
Figure (10) shows the effect of the heat transfer coefficient on the surface and total resistance. The resistances fall sharply from infinity at the small value of $(h)$ as the numerical value of the heat transfer coefficient approaches the thermal conductivity of the fin material. The total resistance starts to decrease slowly because the material resistance then becomes the determining factor in the process. Accordingly, an increase in the heat transfer coefficient lessens the surface resistance against transverse heat flow.

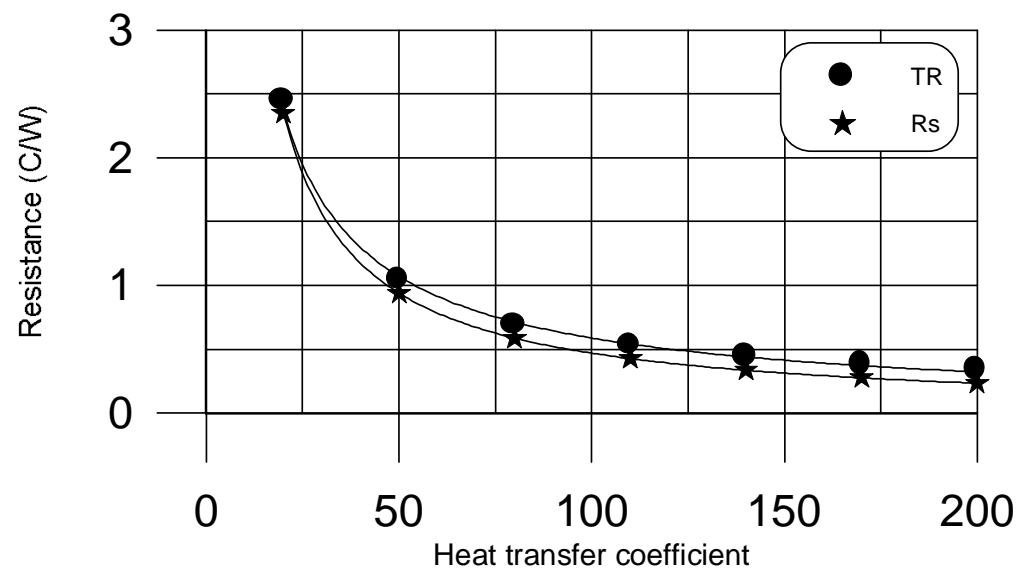

Figure (10) the relation between resistance and heat transfer coefficient

Figure (11) shows the relation between the heat transfer and the total resistance in logarithmic curve. The heat transfer results which are computed numerically and analytically and plotted together for a wide range of outer radius $(0.02-0.06) \mathrm{m}$, heat transfer coefficient from $(20-280) \mathrm{W} / \mathrm{m}^{2}{ }^{\circ} \mathrm{K}$, thermal conductivity from $(50-400) \mathrm{W} / \mathrm{m} .{ }^{\circ} \mathrm{K}$ and fin thickness from (0.001-0.005) $\mathrm{m}$. All points appeared on the same straight line which indicate the sufficiency of the proposed model and its adequacy to describe the phenomena of heat transfer through annular fins variable thickness. The results between the total resistance model and analytical and numerical solution show a good agreement as an evidence to prove the validity of the total resistance model.

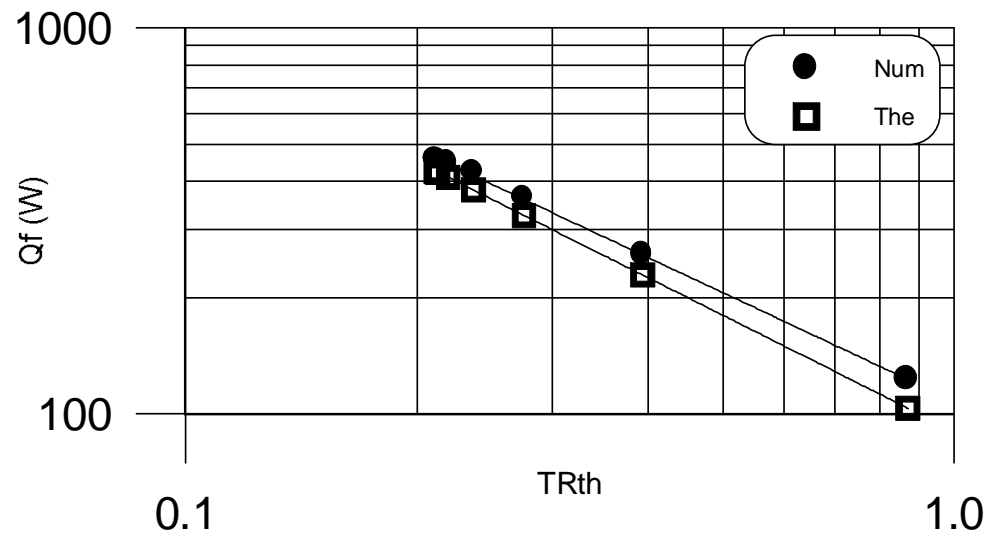

Figure (11) the relation between the heat flow and total resistance 


\section{$\begin{array}{llll}\text { Al-Rafidain Engineering } & \text { Vol.19 } & \text { No.1 } & \text { February } \\ 2011\end{array}$}

\section{Conclusions:}

the important conclusion in this paper is derivative a general equation to calculate the heat transfer from annular fins with variable thicknesses analytically and numerically by dependence on the group of resistances in the radial and transverse directions.

\section{References:}

1-Hegges, P.J., Ingham, D.B. and Manzoor, M.,"The Effect of Non-Uniform Heat Transfer from an Annular Fin of Triangular Profile", Transactions of the ASME, Vol.103, February, 1981.

2-Das,P.K. \& Kunda,B., "Performance Analysis and Optimization of Straight Taper Fins with Variable Heat Transfer Coefficient", Int. J. of Heat and Mass Transfer, pp.47394750, August 2002.

3-Kahwaji, G.Y., "An Analogue System for Heat Flow Through Annular Fin Constant Thickness ", M. Sc. Thesis, University of Mosul, 1979.

4-Al-Makhyoul, Z.M., "Experimentally Validation of the Total Resistance Heat Dissipation Model for Heat Transmission Through Annular Fins", M.SC. Thesis, University of Mosul, 2001.

5-Kahwaji, G.Y. \& Al-Makhyoul, Z.M., "Validation of the Total Resistance Heat Dissipation Model for Heat Transmission Through Annular Fins with Variable Heat Transfer Coefficient", J. of Al-Rafideen, Mousl 2005.

6-Al-Naimey, R., "Experimental Investigation of Total Resistance and Heat Dissipation from Longitudinal Fins", M.SC Thesis, University of Mosul, 2004.

7-John, D. and Anderson, JR., " Computational Fluid Dynamic" the Basic with Applications, McGraw-Hill, Inc. 1995. 